\title{
Juvenile idiopathic arthritis-associated uveitis: Data from a region in western Greece
}

This article was published in the following Dove Press journal:

Clinical Ophthalmology

8 May 2010

Number of times this article has been viewed

\author{
loannis Asproudis' \\ Taxiarchis Felekis' \\ Elena Tsanou ${ }^{2}$ \\ Spiridon Gorezis ${ }^{2}$ \\ Eikaterini Karali ${ }^{3}$ \\ Sapfo Alfantaki ${ }^{3}$ \\ Antigoni Siamopoulou- \\ Mauridou ${ }^{3}$ \\ Miltiadis Aspiotis' \\ 'University Eye Clinic of loannina, \\ Greece; ${ }^{2}$ Epirus Vision Center, \\ loannina, Greece; ${ }^{3}$ Department of \\ Child Health, University of \\ Ioannina, Greece
}

Correspondence: Spiridon Gorezis Panepistimiou Avenue, loannina, 45500 Greece

Tel $+30693619 \mid 12$ |

$\mathrm{Fax}+302651067689$

Email gorezis@hotmail.com
Objective: To evaluate the characteristics and visual prognosis of juvenile idiopathic arthritis-associated uveitis (JIA).

Methods: A retrospective review was performed on 56 patients who met the criteria for JIA to identify those with uveitis and related complications. Patients were referred to and were examined in the Pediatric Department of the University Hospital of Ioannina, between 1995 and 2007.

Results: The prevalence of JIA-associated uveitis was high. Despite this and the related complications, the final visual outcome was satisfactory in the majority of the cases. Authors did not observe any correlation between prognosis and sex, age at the onset of uveitis or arthritis, pattern of arthritis, or positivity for antinuclear antibodies (ANA).

Conclusion: We found a remarkably high prevalence of uveitis and related ocular complications in $7(28 \%)$ of the patients, and the rate of poor visual outcome was $12 \%$.

Keywords: idiopathic arthritis, uveitis, visual complications, autoimmune disease

\section{Introduction}

Juvenile idiopathic arthritis (JIA) is an autoimmune disease ${ }^{1}$ whose association with uveitis is established for more than half a century. ${ }^{2,3,4}$ There are, according to the International League of Associations for Rheumatologists (ILAR), 7 subtypes of JIA known as oligoarticular, polyarticular $\mathrm{RF}(-)$, polyarticular $\mathrm{RF}(+)$, enthesitis-related arthritis, psoriatic arthritis, systemic, and undifferantiated. ${ }^{5}$

The JIA-associated uveitis may develop before, at the same time, or after the arthritis onset. $^{2,6}$ It is typically anterior, chronic, and usually affects both eyes. ${ }^{7-11}$ If untreated, serious ocular complications can occur (cataract, glaucoma, band keratopathy, posterior synechiae) causing visual impairment in afflicted children. ${ }^{2,5,12}$

Risk factors for the development of uveitis in children with JIA, are early onset of the disease, pauciarticular subtype, antinuclear antibodies (ANA) positive titers, female sex, and certain human leukocyte antigen (HLA) markers. ${ }^{13,14}$ All children with JIA should have at least one adequate slit lamp examination as soon as possible after diagnosis of the arthritis. ${ }^{7,12}$ If uveitis is not detected initially, all children with JIA should be screened by slit lamp examination as per specific screening criteria ${ }^{2,3,15,16}$ according to the American Academy of Pediatrics (Table 1). We must mention that the frequency of ophthalmologic examination has been slightly changed, according to updated recommendations, ${ }^{17}$ where the duration of disease (in years) is also taken into consideration.

In the present study we performed a retrospective chart review to study the prevalence, complications, and visual outcome of JIA-associated uveitis patients. 
Table I Classification of JIA

\begin{tabular}{lll}
\hline Classification of JIA & $\begin{array}{l}\text { Frequency of } \\
\text { eye examination }\end{array}$ & Risk \\
\hline $\begin{array}{l}\text { Pauciarticular or polyarticular onset } \\
<7 \text { years of age and ANA }(+)\end{array}$ & Every 3 months & High \\
$\begin{array}{l}\text { Pauciarticular or polyarticular } \\
\text { onset and ANA (-) regardless of age }\end{array}$ & 6 months & Medium \\
$\begin{array}{l}\text { Onset }>7 \text { years of age, regardless of } \\
\text { ANA status }\end{array}$ & 6 months & Medium \\
Systemic onset of JIA & 12 months & Low \\
\hline Ab
\end{tabular}

Abbreviations: ANA, antinuclear antibodies; JIA juvenile idiopathic arthntis.

\section{Patients and methods}

To identify those with uveitis and related complications a retrospective chart review was performed in 56 consecutive patients that fulfilled the ILAR 2001 revised criteria for juvenile rheumatoid arthritis (JRA): ${ }^{5}$ persistent arthritis (swelling of a joint or limitation of motion with heat, pain, or tenderness) of one or more joints for at least 6 weeks after exclusion of infectious, metabolic, traumatic, and neoplastic causes as well as other autoimmune diseases (including psoriatic arthritis, ankylosing spondylitis, inflammatory bowel disease, systemic lupus erythematosus). Those patients were referred to the Pediatric Department of the University Hospital of Ioannina, Greece, between 1995 and 2007 and were examined ophthalmologically in the Pediatric Ophthalmologic Department of our clinic. The pediatric rheumatological database included age, gender, arthritis subgroup, age at onset of arthritis, treatment, arthritis activity, number of swollen or tender joints, and extraarticular manifestations such as the presence of uveitis and uveitis complications. The presence of antinuclear antibodies (ANA), HLA-B27 antigen, and rheumatoid factor $(\mathrm{RF})$ were documented.

The screening intervals met the criteria of the established guidelines, at the time patients were examined..$^{18}$ The mean follow up time was 7.5 years. All patients underwent a thorough ophthalmologic examination including visual acuity or cycloplegic refraction, slit-lamp biomicroscopy, IOP measurement (when possible), and dilated-fundus examination. Visual acuity cut-offs of 20/50 or worse (low vision) and 20/200 or worse (legal blindness) were used according to recommendations from the Standardization of Uveitis Nomenclature (SUN) Working Group. ${ }^{19}$

Statistical analysis was performed with Statistical Package for Social Sciences (version 14.0; SPSS Inc., Chicago, IL). Odds ratios (OR) were calculated using Chi-square tests or Fisher's exact tests where appropriate and $P$ values less than 0.05 were considered statistically significant.

\section{Results}

Fifty-six patients were included in the study with diagnosis of JIA. Thirty-seven (66\%) were girls and 19 (34\%) were boys. The average age at diagnosis of JIA was 65 months (95\% confidence interval [CI]: 51-77 months), range: 3-161 months, median: 54 months.

Anterior uveitis occurred in 25 (45\%) patients during the study period. Sixteen (64\%) were girls and $9(36 \%)$ were boys. It was bilateral in $21(84 \%)$ and unilateral in the other $4(16 \%)$ cases. The average age at diagnosis of JIA of the children who developed uveitis was 56 months (95\% CI: 36-75 months), range: $9-152$ months, median: 36 months. The prevalence was $48 \%$ (14 of 29) in the patients seen before January 2000 and $41 \%$ (11 of 27) in those seen after January 2000.

The diagnosis of uveitis was made within the first 3 years after the diagnosis of JIA for the majority of the patients, specifically for $23(92 \%)$ of them.

In $13(52 \%)$ of the 25 patients, uveitis was diagnosed at the initial eye examination immediately after diagnosis of JIA, while for the remaining 12 (48\%) children, the mean interval from the diagnosis of JIA to the onset of uveitis was 23 months (95\% CI 6-41 months), range: 3-89 months, median: 12 months.

Oligoarticular JRA is defined by involvement of 4 or fewer joints; polyarticular JRA is defined by involvement of $>4$ joints (usually 10-20); and systemic-onset JRA is defined by quotidian fevers during the first 6 weeks of the illness, almost always associated with a characteristic rash. Of the 56 patients with JIA, 42 (75\%) were classified as having the oligoarticular onset subtype, $10(18 \%)$ as polyarticular and $4(7 \%)$ had the systemic onset subtype. Of the 25 patients who developed uveitis, 21 (84\%) were classified as having oligoiarticular onset JIA, 4 (16\%) had polyarticular onset JIA and none had systemic JIA (Table 2). The subtype of JIA did not constitute a statistically signigicant risk factor in our study $(P$-value $=0.17$, using the Fisher's exact test $)$.

Of the 56 patients, ANA titers were positive in $52(93 \%)$ and negative in only 4 (7\%) of them. Of the 25 patients with uveitis, 24 (96\%) had positive ANA titers and only 1 (4\%) had negative ANA titers (Table 3). In this case also, ANA positive titers did not constitute a statistically significant risk factor $(P$-value $=0.62$, using the Fisher's exact test $)$.

Table 2 Uveitis and JIA subtype

\begin{tabular}{llll}
\hline Subtype & $\begin{array}{l}\text { Uveitis } \\
(\mathbf{n}=25)\end{array}$ & $\begin{array}{l}\text { No uveitis } \\
(\mathbf{n}=31)\end{array}$ & $\begin{array}{l}\text { Total } \\
(\mathbf{n}=56)\end{array}$ \\
\hline Pauci- & $2 I(84 \%)$ & $21(68 \%)$ & $42(75 \%)$ \\
Poly- & $4(16 \%)$ & $6(19 \%)$ & $10(18 \%)$ \\
Systemic & 0 & $4(13 \%)$ & $4(7 \%)$ \\
\hline
\end{tabular}

Abbreviation: JIA, juvenile idiopathic arthritis. 
Table 3 ANA titers and uveitis

\begin{tabular}{llll}
\hline $\begin{array}{l}\text { ANA } \\
\text { titers }\end{array}$ & $\begin{array}{l}\text { Uveitis } \\
(\mathbf{n}=\mathbf{2 5})\end{array}$ & $\begin{array}{l}\text { No uveitis } \\
(\mathbf{n}=\mathbf{3 I})\end{array}$ & $\begin{array}{l}\text { Total } \\
(\mathbf{n}=\mathbf{5 6})\end{array}$ \\
\hline Positive & $24(96 \%)$ & $28(90 \%)$ & $52(93 \%)$ \\
Negative & $\mathrm{I}(4 \%)$ & $3(10 \%)$ & $4(7 \%)$ \\
\hline
\end{tabular}

Abbreviation: ANA, antinuclear antibodies.

Visual complications occurred in $7(28 \%)$ of the 25 patients with uveitis (Figures 1-4). Frequencies of poor visual acuity at presentation were assessed. Poor visual outcome occurred in $3(12 \%)$ of the patients with uveitis. One patient (suffering from phthisis bulbi, see Figure 4) lost vision and two others had loss of vision up to counting fingers. None of the rest 22(88\%) patients had visual acuity less than $7 / 10$, while $15(60 \%)$ of them had visual acuity equal to $10 / 10$ and $19(76 \%)$ equal or more than $9 / 10$. All these complications presented latter in the disease course. Cataract developed in six (treated surgically with implantation of anterior chamber intraocular lens) and glaucoma in one (initially treated with antiglaucomatic drugs and later with trabeculectomy). Four patients developed band keratopathy (treated with abrasion and use of EDTA), one patient had phthisis bulbi, another had hyphema and three developed posterior synechiae (Table 4).

Concerning the therapy, 11 children were treated with methotrexate, three with a combination of methotrexate and methylprednisolone; 10 children were treated with the use of biological factors, such as the tumor necrosis factor (TNF)-blocking agents etanercept and infliximab; and the rest were treated with nonsteroidal anti-inflammatory agents. Iridocyclitis was confronted with atropine, anti-inflammatory, and cortisone drops.

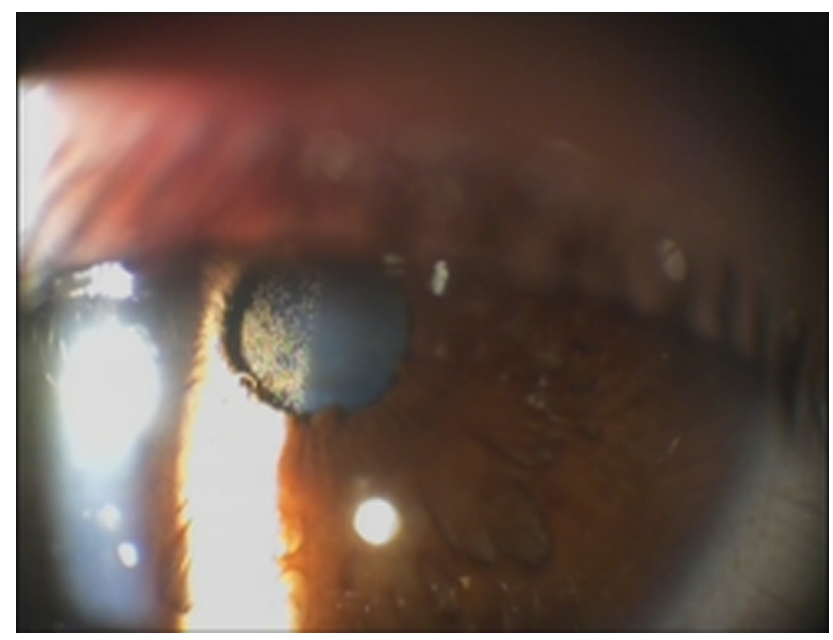

Figure I Cataract and thin precipite.

\section{Discussion}

Juvenile idiopathic arthritis is an autoimmune disease that can cause great inconvenience in the young patient's life. The prevalence of uveitis at children with JIA, ${ }^{8,9}$ has been found to be between $4 \%$ and $24.4 \%$, even though there are sporadic studies showing a much greater prevalence. It is typically anterior, nongranulomatous, and usually bilateral. Chronic iridocyclitis accounts for about $90 \%$ of the cases and if untreated, serious visual impairment may occur. It is important to consider that up to $80 \%$ of all cases of anterior uveitis in childhood are associated with JIA, thus rendering it the most common cause of chronic iridocyclitis in children. ${ }^{19-21}$

The prevalence of uveitis in our study was $45 \%$. It is one of the highest observed in most studies, especially given the fact that it concerns all types of JIA and not only selectively the oligoarticular. The confusingly different prevalence rates observed in the literature, can be attributed to the different study designs, as some of them concern population-based data and others large rheumatology centers with different selection criteria and follow-up. Furthermore, these differences may derive from the social and environmental factors of the patients included in the various studies.

We wanted to find out whether this high rate was due to older cases and whether there is a decreasing tendency over the last decade. The difference between the two groups was quite small. A similar observation was made by Kodsi et al in 2002. ${ }^{2}$

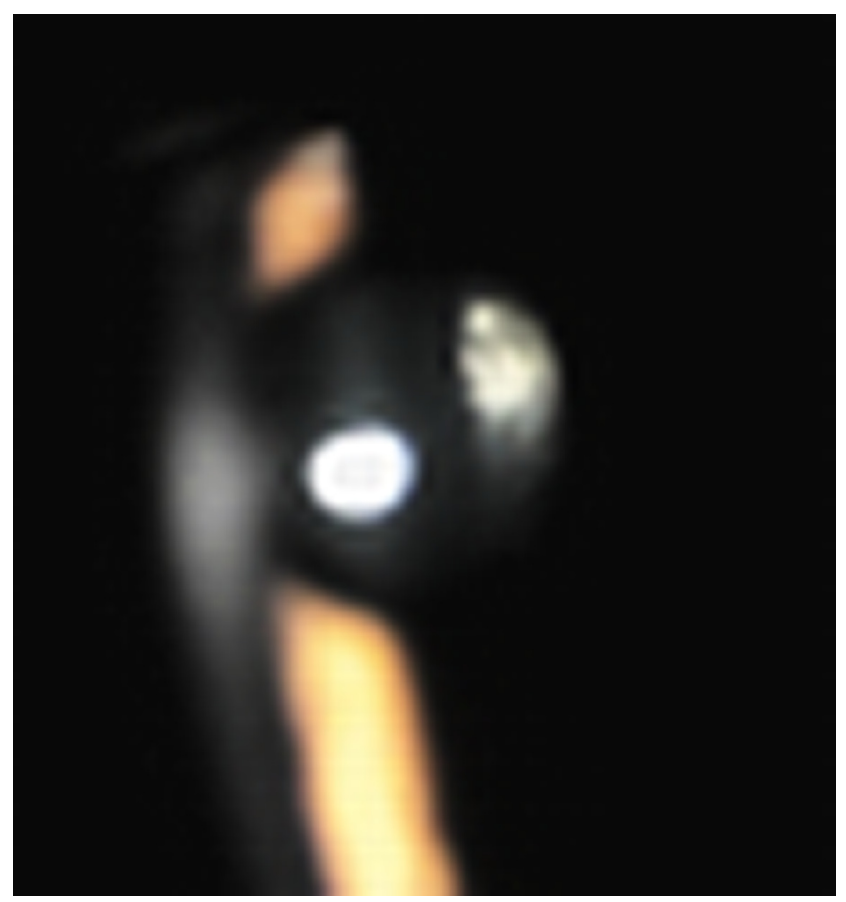

Figure 2 Posterior subcapsular cataract. 


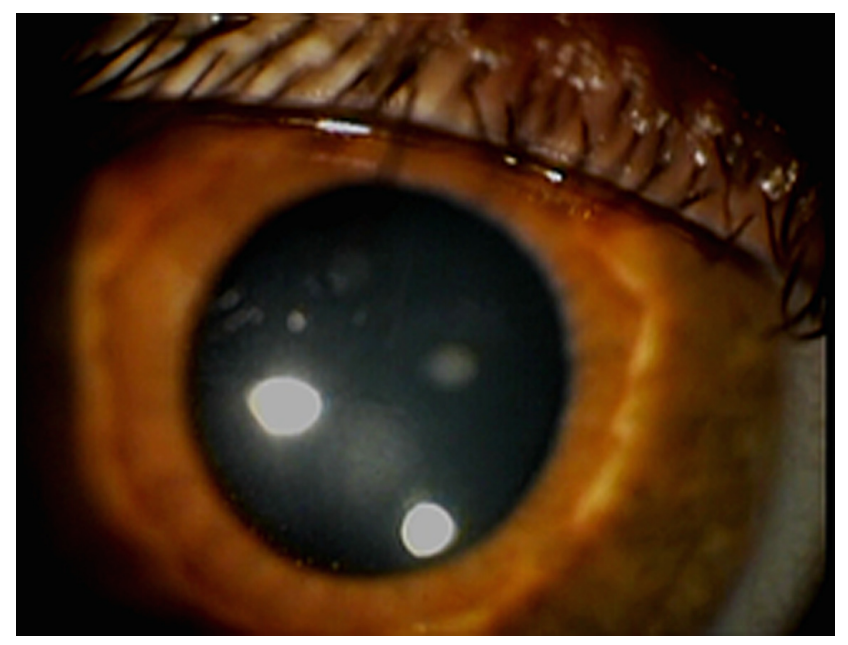

Figure 3 Inflammatory elements on the anterior capsule of the lens.

A significant characteristic of these children is that they rarely complain of pain or 'red eye', as the onset is often asymptomatic and insidious. As uveitis progresses and when they begin to complain of visual disturbances, they have already developed serious complications (cataract, glaucoma, band keratopathy, cystoid macular edema etc). ${ }^{23}$ Most patients have seronegative disease for rheumatoid factor while the most common serological finding is the presence of ANA antibodies which are detected in $96 \%$ of uveitis cases. ANA titers constitute a nonspecific finding since they may be present in other autoimmune diseases, malignancies, and aging and they are unassociated with disease activity or severity. ${ }^{24}$ According to studies, the presence of ANA should prove useful in identifying patients with JIA at risk for chronic anterior uveitis. ${ }^{2}$

Another significant risk factor is the subtype of JIA. $80 \%-90 \%$ of cases of JIA-associated uveitis suffer from

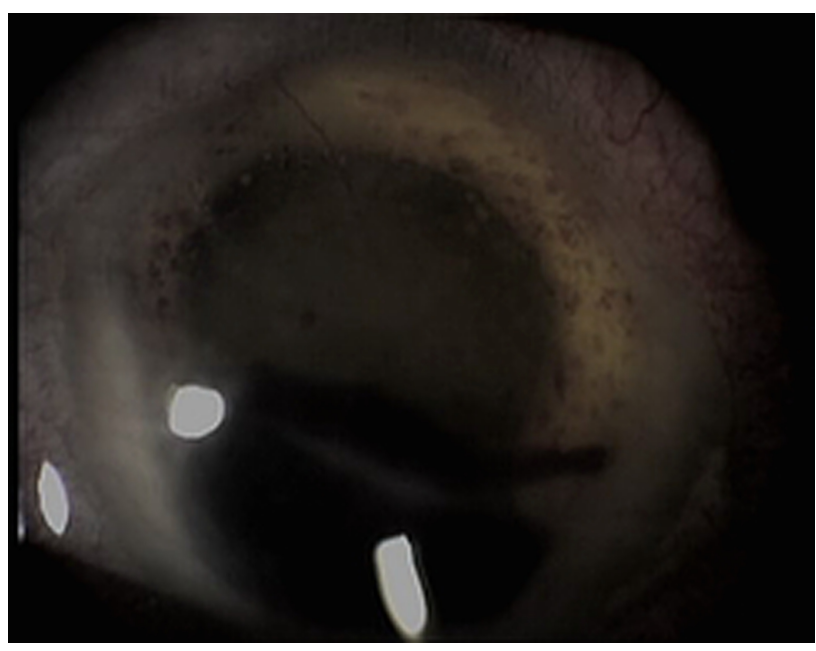

Figure 4 Phthisis bulbi and hyphema.
Table 4 Visual complications

\begin{tabular}{ll}
\hline Visual complications & Number of patients(\%) \\
\hline Cataract & $6(24 \%)$ \\
Glaucoma & $\mathrm{I}(4 \%)$ \\
Posterior Synechiae & $3(12 \%)$ \\
Band Keratopathy & $4(16 \%)$ \\
Phthisis Bulbi & $\mathrm{I}(4 \%)$ \\
Hyphema & $\mathrm{I}(4 \%)$ \\
\hline
\end{tabular}

oligoarticular arthritis, 7\%-14\% from polyarticular and $2 \%-6 \%$ presents the systemic subtype. ${ }^{19,26}$

What might be interesting, is the fact that despite the established association of uveitis with the presence of oligoarticular JIA and presence of antinuclear antibodies, ${ }^{14,26}$ in our study oligoarticular onset subtype of JIA or ANA positive titers did not constitute a statistically significant risk factor $(P>0.05)$. As in all retrospective studies, our results must be interpreted with caution. A referral bias exists because our institution is a tertiary care medical center, and it is possible that only the most severe cases of JIA associated uveitis were referred to our center as suggested by high frequencies of ocular complications and poor visual acuity as well as the long duration of uveitis prior to presentation to our clinic. Furthermore, the number of events was small for some outcomes, which may have limited the precision of odds ratios for certain risk factors. Despite these limitations, our study suggests that visual impairment still occur frequently in JIA-related uveitis, seen in the tertiary care setting. Almost equally high rates of oligoarticular onset subtype of JIA and ANA positive titers were found among children who did not develop uveitis throughout any stage of the follow up.

In our study visual complications occurred in 7(28\%) of the 25 patients with uveitis. Severe visual impairment has been reported in up to $38 \%$ of patients. ${ }^{27-28}$ Increased severity of ocular disease at the initial examination has been reported as a risk factor for poor visual acuity outcomes at the last follow-up visit, but the follow-up time in these series are variable. 29,30

One patient developed uveitis 6 years later and another one almost 7.5 years later. Both of them were males, suffering from bilateral uveitis, were ANA positive, and HLA-B27 negative; one suffering oligoarticular and the other from polyarticular JIA.

\section{Conclusion}

The range of cumulative incidence of JRA-associated uveitis has been reported to be between $1.4 \%-38 \% \%^{2,31-36}$ Our analysis suggested a cumulative incidence of JRA-associated uveitis at the high end of the above mentioned rates. As a conclusion, 
we observed remarkably high prevalence of uveitis and related ocular complications in 7 (28\%) of the patients and furthermore the rate of poor visual outcome was almost $12 \%$. The reported rate of visual loss due to JRA-related uveitis varies in more recent studies from $3 \%-25 \% .{ }^{26}$ All these documentations may facilitate the optimization of the current guidelines and result in optimization of follow up. Immediate ophthalmological examination after the diagnosis of JIA and excellent co-operation between the physician and the parents of the children concerning the therapy may help to improve long-term outcome.

\section{Disclosures}

No conflicts of interest were declared in relation to this paper.

\section{References}

1. Leak A, Woo P. Juvenile chronic arthritis, chronic iridocyclitis and reactivity to histones. Ann Rheumatol Dis. 1991;50(9):653-657.

2. Kodsi RS, Rubin ES, Milojevic D, Ilowite N, Gottlieb B. Time of onset of uveitis in children with juvenile rheumatoid arthritis. $J$ AAPOS. 2002;6(6):373-376.

3. Oren B, Sehgal A, Simon WJ, et al. The prevalence of uveitis in juvenile rheumatoid arthritis. JAAPOS. 2001;5(1):2-4.

4. Kanski JJ. Juvenile arthritis and uveitis. Survey Ophthalmol. 1990;34(4):253-257.

5. International League of Associations for Rheumatology. International League of Associations for Rheumatology classification of juvenile idiopathic arthritis: second revision, Edmonton. 2001. J Rheumatol. 2004;31(2):390-392.

6. Arnason JA, Bell CL. Juvenile rheumatoid arthritis: current concepts and practice. J Pediatric Ophthalmol Strabismus. 1995;32(6):383-385.

7. Nguyen QD, Foster S. Saving the vision of children with juvenile rheumatoid arthritis-associated uveitis. JAMA. 1998;280(13):1133-1135.

8. Chylack LT. The ocular manifestations of juvenile rheumatoid arthritis. Arthritis Rheumatol. 1977;20(Suppl 2):217-223.

9. Kotaniemi K, Kautiainen H, Karma A, Aho K. Occurrence of uveitis in recently diagnosed juvenile chronic arthritis. A prospective study. Ophthalmology. 2001; 108:2071-2075.

10. De Boer J, Wulffraat N, Rothova A. Visual loss in uveitis of childhood. Br J Ophthalmol. 2003;87(7):879-884.

11. Sijssens KM, Rothova A, Berendschot TTJM, de Boer JH. Ocular hypertension and secondary glaucoma in children with uveitis. Ophthalmology. 2006;113(5):853-859.

12. Leak MA. Ophthalmological screening in seronegative juvenile chronic arthritis: a personal view. Br J Rheumatol. 1992;31(9):631-633.

13. SouthwoodTR, Ryder CAJ. Ophthalmological screening in juvenile arthritis:should the frequency of screening be based on the risk of developing chronic iridocyclitis? Br J Rheumatol. 1992;31(9):633-634.

14. Chen CS, Roberton D, Hammerton ME. Juvenile arthritis-associated uveitis: visual outcomes and prognosis. Can J Ophthal. 2004;39(6): 614-620.

15. Boone IM, Moore LT, Cruz AO. Screening for uveitis in juvenile rheumatoid arthritis. J Pediatric Ophthalmol Strabismus. 1998;34:41-43.

Clinical Ophthalmology

\section{Publish your work in this journal}

Clinical Ophthalmology is an international, peer-reviewed journal covering all subspecialties within ophthalmology. Key topics include: Optometry; Visual science; Pharmacology and drug therapy in eye diseases; Basic Sciences; Primary and Secondary eye care; Patient Safety and Quality of Care Improvements. This journal is indexed on Submit your manuscript here: http://www.dovepress.com/clinical-ophthalmology-journal
16. Candell Chalom E, Goldsmith PD, Koehler AM, et al. Prevalence and outcome of uveitis in a regional cohort of patients with juvenile rheumatoid arthritis. J Rheumatol. 1997;24:2031-2034.

17. Cassidy J, Kivlin J, Nocton J. Ophthalmologic examinations in children with juvenile rheumatoid arthritis. Pediatrics. 2006;117(5):1843-1845.

18. American Academy of Pediatrics. Section on Rheumatology and Ophthalmology. Guidelines for ophthalmologic examination in children with juvenile rheumatoid arthritis. Pediatrics. 1993;92(2):295-296.

19. Jabs DA, Nussenblatt RB, Rosenbaum JT. Standardization of uveitis nomenclature for reporting clinical data: results of the First International Workshop. Am J Ophthalmol. 2005;140:509-516.

20. Kanski JJ, Shun Shin A. Systemic uveitis syndromes in childhood. An analysis of 340 cases. Ophthalmology. 1984;91(10):1247-1251.

21. Giles CL. Uveitis in childhood. Ann Ophthal. 1989;21(1):13-19.

22. Avery H, Weiss HA, Wallace AC, Sherry DD. Methotrexate for resistant chronic uveitis in children with juvenile rheumatoid arthritis. J Pediatric. 1998;133(2):266-268.

23. Wolf MD, Lichter PR, Ragsdal CG. Prognostic factors in the uveitis of juvenile rheumatoid arthritis. Ophthalmology. 1987;94(10):1242-1248.

24. Malleson PN, Sailer M, Mackinnon MJ. Usefulness of antinuclear antibody testing to screen for rheumatic diseases. Arch Dis Child. 1997;77:299-304.

25. Carvounis Petros E, Herman David C, Cha Stephen, Burke James P. Incidence and outcomes of uveitis in juvenile rheumatoid arthritis, a synthesis of the literature. Graefe's Arch Clin Exp Ophthalmol. 2006;244(3):281-290.

26. Saurenmann RK, Levin AV, Feldman BM, et al. Prevalence, risk factors, and outcome of uveitis in juvenile idiopathic arthritis: a long-term followup study. Arthritis Rheum. 2007;56(2):647-657.

27. Key SN, Kimura SJ. Iridocyclitis associated with juvenile rheumatoid arthritis. Am J Ophthalmol. 1975;80:425-429.

28. Özdal PC, Vianna RN, Deschênes J. Visual outcomes of juvenile rheumatoid arthritis-associated uveitis in adults. Ocul Immunol Inflamm. 2005;13:33-38.

29. Edelsten C, Lee V, Bentley CR, et al. Visual outcomes prognosticators in juvenile rheumatoid arthritis-associated uveitis. Ophthalmology. 1997;104:236-244.

30. Graham EM. An evaluation of baseline risk factors predicting severity in juvenile idiopathic arthritis associated uveitis and other chronic anterior uveitis in early childhood. Br J Ophthalmol. 2002;86:51-56.

31. Singh S, Salaria M, Kumar L, Minz R, Data U, Sehgal S. Clinicoimmunologicalprofile of juvenile rheumatoid arthritis. Ind Pediatr. 1999;36:449-454.

32. Arguedas O, Fasth A, Andersson-Gare B, Porras O. Juvenile chronic arthritis in urban San Jose, Costa Rica: a 2 year prospective study. J Rheumatol. 1998;25:1844-1850.

33. Berk AT, Kocak N, Unsal E. Uveitis in juvenile arthritis. Ocul Immunol Inflamm. 2001;9: 243-251.

34. Dracou C, Constantinidou N, Constantopoulos A. Juvenile chronic arthritis profile in Greek children. Acta Paediatr Jpn. 1998;40: 558-563.

35. Fujikawa S, Okuni M. Clinical analysis of 570 cases with juvenile rheumatoid arthritis: results of a nationwide retrospective survey in Japan. Acta Paediatr Jpn. 1997;39:245-249.

36. Moe N, Rygg M. Epidemiology of juvenile chronic arthritis innorthern Norway: a ten-year retrospective study. Clin Exp Rheumatol. 1998;16:99-101.

\section{Dovepress}

PubMed Central and CAS, and is the official journal of The Society of Clinical Ophthalmology (SCO). The manuscript management system is completely online and includes a very quick and fair peer-review system, which is all easy to use. Visit http://www.dovepress.com/ testimonials.php to read real quotes from published authors. 